\title{
Family status and later-life depression among older adults in urban Latin America and the Caribbean
}

\author{
Nekehia T. Quashie ${ }^{1 \star}$ and Flavia C.D. Andrade ${ }^{2}$ \\ ${ }^{1}$ College of Population Studies, Chulalongkorn University, Bangkok, Thailand and ${ }^{2}$ Department of \\ Kinesiology and Community Health, University of Illinois at Urbana-Champaign, Champaign, IL, USA \\ ${ }^{*}$ Corresponding author. Email: Nekehia.Q@chula.ac.th
}

(Accepted 12 June 2018; first published online 7 August 2018)

\begin{abstract}
Rapid fertility declines in Latin American and Caribbean countries since the 1960s have contributed to smaller family sizes among the current cohorts of older adults. This may have mental health implications in these societies as the family unit is highly valued as a source of social support. Utilising data from the 2000 Survey of Health, Well-being and Aging in Latin America and the Caribbean (SABE), this study examines the association between parental status, marital status and the likelihood of experiencing depressive symptoms among adults 60 years and older in seven cities within Latin America and the Caribbean $(\mathrm{N}=9,756)$ : Buenos Aires, Bridgetown, São Paulo, Santiago, Havana, Mexico City and Montevideo. Results from multivariate logistic regressions indicate that parental status is not significantly associated with depressive symptoms. Nonetheless, unmarried older adults, both those living alone and those living with others, are more vulnerable to experiencing depressive symptoms than their married counterparts. Marriage is especially protective for older adults in Havana and Montevideo. Older adults' perceived income adequacy significantly moderates the relationship between marital status and depressive symptoms. Other significant covariates, such as experiencing disability and comorbidity, showed positive associations with depressive symptoms. While families may still represent a critical component for the mental health of older adults, broader investments in health across the lifespan are needed to improve individual psychological wellbeing.
\end{abstract}

Keywords: depression; ageing; children; marriage; income adequacy; Latin America; Caribbean

\section{Introduction}

Depressive disorders are a major cause of disease burden worldwide. According to estimates drawn from the 2010 Global Burden of Disease, 298 million (4.4\%) adults have major depressive disorders (Ferrari et al., 2013). In Latin American and Caribbean countries, prevalence rates of major depressive disorders are generally low, and vary across countries: Mexico (3.0\%), Chile (4.0\%), Uruguay (4.7\%), 
Argentina (5.2\%), Barbados (5.3\%), Brazil (5.5\%) and Cuba (5.8\%) (Ferrari et al., 2013). Nonetheless, prevalence rates of major depressive disorders among older adults in the region are relatively low when compared to the prevalence of depressive symptoms (Brailean et al., 2015). As observed globally, the prevalence rates of depressive symptoms in Latin American and Caribbean countries are higher among women and increase with age (Guerra et al., 2016).

Although limited, the existing research on depression among older adults in Latin America and the Caribbean has identified health impairments, lower socioeconomic conditions (particularly educational levels) and being female as the common correlates (Alvarado et al., 2007; Carvalhais et al., 2008; Guerra et al., 2009; Ylli et al., 2016). One social feature that has not yet been examined within Latin American and Caribbean contexts is the role of family resources, particularly the availability of adult children, in contributing to later-life depression. Due to declining fertility and increased marital dissolution, older adults in the region will likely experience a reduced supply of their familial resources.

In Latin America and the Caribbean, fertility rates declined from 5.9 at the beginning of the 1960s to 2.8 children per woman by the 1995-2000 period (United Nations (UN), 2017a). This trend signifies a marked reduction in family sizes and increases in the likelihood that future cohorts of older adults will be childless. Other changes in household composition and family structures (Rosero Bixby et al., 2009; García and De Oliveira, 2011), alongside longer life expectancy, may increase the likelihood of older persons living alone or with only their spouses for a larger portion of their lives (Palloni, 2001; Bongaarts and Zimmer, 2002). Although previous studies indicate that children are important for older adults' wellbeing, their significance also depends on individual circumstances including gender and marital status, and experiences of stressors such as financial strain, as well as national-level characteristics, such as the cultural ideals of family life, social welfare and social services (Haberkern and Szydlik, 2010; Mair, 2013; Grundy et al., 2017; Neuberger and Preisner, 2018). Research also shows that living alone can jeopardise older adults' mental health, especially in societies with weaker social welfare infrastructure or high regard for family ties (Chou et al., 2006; Gaymu and Springer, 2010; Greenfield and Russell, 2011). Given the demographic changes facing the region, examining the relationship between family ties and older adults' mental health within Latin American and Caribbean contexts is a timely and important area of research.

Changes in family size and composition can contribute to the diminished mental health of Latin American and Caribbean older adults. Although there have been improvements in the formal provision of pensions, health care and other social services for the region's older adults since the turn of the century, significant inequality in coverage and access to public services remains (Huenchuan, 2013). In Latin America and the Caribbean, income security at older ages remains one of the most important challenges, despite reforms to improve pension coverage. In 2000, approximately 34 per cent of older adults 65 years and older in Latin America and the Caribbean received a contributory pension and by 2010 this proportion had increased to approximately 40 per cent (Bosch et al., 2013; Huenchuan, 2013). Health systems are also challenged to provide equality in the coverage, accessibility and quality of services provided, high levels of out-of-pocket expenditure are 
still common across several countries in the region (Pan American Health Organization, 2017), and state-funded initiatives in community care systems are still underdeveloped though more common in English-speaking Caribbean countries relative to Latin America (Huenchuan, 2013). As a result of the limited formal assistance, the family unit remains a significant source of financial, instrumental and social support for older adults (Calvo and Williamson, 2008; De Vos, 2012). Nevertheless, there are cross-national differences in older adults' reliance on familial resources, particularly for financial support. Cotlear and Tornarolli (2011) show that in countries categorised as having high pension coverage, such as Uruguay, Argentina and Brazil, pensions account for a significant proportion of older adults' income relative to private transfers from family or other social networks. However, in countries with low pension coverage, such as in Mexico, the reverse is observed.

Pension coverage is certainly important but, for many older adults, the income provided by this source is insufficient to provide an adequate standard of living. Perceived income adequacy, which depends on local social norms of expenditure and lifestyle, has been shown to be a more reliable indicator of older adults' financial wellbeing and health status (Angel et al., 2003; Litwin and Sapir, 2009; Arber et al., 2014; Gildner et al., 2016). For instance, economic security and adequacy have been shown to be protective factors for depression (Guerra et al., 2009), selfrated health and quality of life (Arber et al., 2014; Gildner et al., 2016).

Overall, the majority of existing research on family ties, specifically parental and marital status, and mental health in later life, has been conducted in developed countries (Umberson et al., 2010). Among developing countries, there is a growing body of research in China (Cheng et al., 2013; Guo, 2014). We contribute to the literature in developing countries by examining the role of family ties to the mental health of older adults within another developing and rapidly ageing region, Latin America and the Caribbean. Using pooled cross-sectional data from the 2000 Survey of Health, Well-being and Aging in Latin America and the Caribbean, SABE (Peláez et al., 2006), this study explores the relative importance of the family unit, specifically parental and marital status, to older adults' experiences of depressive symptoms in seven cities within Latin America and the Caribbean. Furthermore, our study examines the interplay of parental status, marital status and individuals' experiences of life stressors, specifically perceived income adequacy, in influencing older adults' experiences of depressive symptoms. Finally, given the cities included in this study are located in countries that are at different stages of the demographic transition and vary significantly in socioeconomic conditions, we examine cross-city variations in the associations between each parental status and marital status, and depressive symptoms.

Although these data may not reflect the contemporary contexts of older adults in the region, the main strength lies in the ability to compare settings in different stages of the demographic transition. Given our primary motivation is to assess the relative importance of family resources to the psychological wellbeing of older adults embedded in diverse contexts within the region, the SABE is the only existing cross-national study that offers the opportunity to compare older adults in several countries within the region. Importantly, the analyses allow us to reflect on the relative significance of the availability of family resources for older adults' wellbeing at the beginning of the 21st century. As the ageing process 
continues in the region, albeit with variations in pace, these data allow us to explore how family size and structure contribute to the wellbeing of older adults across different settings in Latin America and the Caribbean.

In addition, we acknowledge that these cities are neither representative of their respective countries nor of all urban areas within their countries. Nonetheless, approximately 75 per cent of the population of Latin America and the Caribbean lived in urban areas in 2000, which is similar to the urbanisation levels of North America and Europe, and higher than other developing regions (Cohen, 2006). This high proportion of individuals living in urban areas means that older adults in urban areas are more likely to access social and health services, which can reduce their reliance on informal support. On the other hand, urban areas are marked by high income inequality and poverty, which means that access to services are not equitable (De Ferranti et al., 2004; Cohen, 2006). These cities, however, represent a range of demographic and socio-economic contexts. Exploring these contexts can help us understand how parenthood, marital status, and socio-economic contexts can influence the mental health of older adults in the region.

\section{Family ties and health}

There is a general consensus that social ties, and the social support drawn from these relationships, are directly and indirectly associated with later-life physical and mental health (Thoits, 2011). While the direct effect model proposes that the availability of social ties is positively associated with health outcomes independent of individuals' experiences of stress, the indirect or stress-buffering model argues that social ties are beneficial to one's health only in the presence of a stressor. Even though there is support for both models, evidence points to stronger and more consistent support for the direct effect than the indirect stress-buffering role of social ties (Thoits, 2011; Tajvar et al., 2016).

Social ties to family members are differentiated from ties to other social groups by an intimate and enduring bond that influences social integration, behaviour and ultimately wellbeing across the lifespan (Elder and Johnson, 2003). Family ties, primarily spouses and adult children, form an important component of older adults' social networks (Connidis, 2010). The availability of spouses and children may enhance later-life mental health through intangible benefits such as providing a sense of belonging as well as meaning and purpose to life that can indirectly influence healthy lifestyle habits and worldviews, thereby fostering positive mental health (Thoits, 2011; Umberson et al., 2013). Furthermore, spouses and adult children are often the primary sources of instrumental, financial and emotional support that help buffer stressful circumstances in later life (Agree and Glaser, 2009). On this basis, childless and unmarried older adults are perceived to be more vulnerable to experiencing worse health outcomes relative to older adults who are married and have children, as they may not experience the benefits that are associated with social ties developed through the parent-child or marital relationship.

The relative benefits of parenthood and partnership, however, also depend on the quality of marital and intergenerational relationships (Umberson et al., 2013). Intergenerational relations are not exempt from conflict between parents 
and their adult children even within societies that attach high value to familial bonds, which can challenge the presumed benefits of having children for mental health (Guo et al., 2012). Likewise, the health benefits of marriage also depend on the quality of marital relations. Strained or unfulfilling marriages are associated with physical and mental health declines (Hank and Wagner, 2013; Liu and Waite, 2014).

The empirical evidence regarding the significance of parenthood to later-life health outcomes presents mixed results. Studies among more developed countries show that the relative significance of childlessness to health, social and economic outcomes depends on individual circumstances such as health status, financial vulnerability, gender, marital status and socio-economic context (Dykstra and Hagestad, 2007; Neuberger and Preisner, 2018).

Regarding gender differences, childlessness is considered to be more detrimental to women's psychological wellbeing than to men's due to gendered social norms that place a higher value on motherhood relative to fatherhood, and women's traditional domestic and kin-keeping social roles (Dykstra and Hagestad, 2007). However, the empirical evidence is inconclusive, with some studies showing childlessness to be more critical for women's psychological wellbeing but unrelated to men's (Koropeckyj-Cox, 1998), while others show that childless men experience worse psychological wellbeing (Buber and Engelhardt, 2008; Huijts et al., 2013). Finally, some studies show no gender differences in the relationship between parenthood and depression (Hank and Wagner, 2013).

The significance of children to later-life wellbeing is further conditioned by social, economic, institutional and cultural contexts. For instance, studies within North America (Koropeckyj-Cox, 1998; Zhang and Hayward, 2001; Chang et al., 2010) and in Nordic countries (Hansen et al., 2009) have indicated that childless older adults do not differ from older adults with children in their levels of depression. In contrast, studies among older Chinese adults have consistently shown mental health disadvantages among childless older adults relative to parents (Chou and Chi, 2004; Zhang and Liu, 2007; Guo, 2014). A reasonable explanation for differing results lies in cultural and social policy differences. In China, the responsibility of children to their older parents is culturally embedded and reinforced by the government (Zhang and Liu, 2007; Guo, 2014). In contrast, in North America and Northern European countries, formal services provided by the state and marketplace complement family support (Davey et al., 2005). Thus, the psychological wellbeing of older adults with and without children may depend on the availability and access to formal services.

Furthermore, individual's economic hardship and broader economic contexts within and between countries also moderate the relationship between parenthood and wellbeing. Research among European countries shows that parenthood is associated with enhanced quality of life among older persons who are experiencing financial hardship and live in countries with lower Gross Domestic Product (GDP). In contrast, childless older adults who experience financial hardship in countries with higher GDP enjoy a better quality of life (Neuberger and Preisner, 2018). Similarly, research among Chinese older adults indicates within-country differences in economic development exert significant influence on the mental health implications of later-life childlessness such that rural childless older adults are more 
vulnerable to depression whereas urban parents and childless do not differ in their mental health (Djundeva et al., 2017).

In contrast to parenthood, most research surrounding the marital status and wellbeing relationship shows more consistently that marriage has significant bearing on later-life mental health. Marriage offers several potential benefits to couples that span the accumulation, and sharing, of economic and non-economic resources (Brown and Wright, 2017). As noted by Umberson et al. (2013), the psychological advantages of marriage are typically understood in reference to the disadvantageous mental health of spousal loss rather than being married per se. Substantial evidence, across diverse social contexts, supports that the unavailability of a partner can be detrimental to one's mental health (Zhang and Li, 2011; Kamiya et al., 2013; Ylli et al., 2016). Moreover, some studies show that marital status is sometimes more pertinent than parental status to older adults' mental health (Koropeckyj-Cox, 1998; Zhang and Hayward, 2001; Hank and Wagner, 2013).

Researchers have posited that the loss of social and instrumental support provided by a spouse, particularly for men, helps to explain the psychological declines associated with marital loss through widowhood (Dalgard et al., 2006). The loss of a spouse/partner either through widowhood, divorce or separation can present financial vulnerabilities due to the absence of an additional source of household income, which can prompt additional psycho-social stress as one adjusts to the loss of socioemotional support in addition to readjusting lifestyles and managing income to meet daily needs. Research shows that widowed older adults not only have lower incomes and experience more financial strain than their married counterparts but the poor health outcomes, physical and mental, of unmarried older adults are also mediated by perceptions of their income adequacy (Arber, 2004; Min et al., 2017). Socio-economic resources also moderate the relationship between marital status and depression, as some studies show that unmarried older adults with higher incomes have better subjective wellbeing than those with lower incomes (Fry, 2001), but other studies show that subjective income does not have a moderating effect on mental health (Min et al., 2017).

\section{Latin America and the Caribbean context: brief overview}

The Latin America and Caribbean region is undergoing rapid population ageing. As shown in Table 1, the proportion of older adults 60 years and over accounted for approximately 8 per cent of the region's total population in 2000, and estimates suggest their proportion will increase to 25 per cent by 2050 (UN, 2017a). Population ageing is, however, not a homogeneous phenomenon across the region as countries differ in their stages in the demographic transition. Among the countries covered in this study, Argentina, Brazil, Uruguay, Chile and Mexico are classified as being at an advanced stage of demographic transition, while Cuba and Barbados are among the most advanced (Saad, 2011).

These differences are influenced by the pace of fertility declines, with Cuba and Barbados showing the lowest fertility rates. Differences in life expectancy are also evident: Cuba and Chile reported the highest life expectancy (76 years) during 1995-2000 whereas lower life expectancy levels were reported in Uruguay (74 years), Mexico (74 years), Argentina (73 years), Barbados (73 years) and Brazil 
Table 1. Demographic and socio-economic indicators for the Latin America and Caribbean (LAC) region and select countries

\begin{tabular}{|c|c|c|c|c|c|c|c|c|}
\hline Country characteristics & Argentina & Uruguay & Barbados & Cuba & Chile & Brazil & Mexico & LAC \\
\hline \multicolumn{9}{|l|}{ Demographic indicators: } \\
\hline Total population (thousands) (2000) ${ }^{1}$ & 37,057 & 3,321 & 270 & 11,151 & 15,263 & 175,288 & 101,720 & 525,795 \\
\hline Total fertility rate $(1995-2000)^{1}$ & 2.6 & 2.3 & 1.7 & 1.6 & 2.2 & 2.5 & 2.9 & 2.8 \\
\hline Life expectancy at birth $(1995-2000)^{1}$ & 73.3 & 74.3 & 72.9 & 76.2 & 76.1 & 68.9 & 73.7 & 70.5 \\
\hline \multicolumn{9}{|l|}{ Population $60+$ years $(\%):^{1}$} \\
\hline 2000 & 13.5 & 17.4 & 15.1 & 13.8 & 10.5 & 7.7 & 7.1 & 8.1 \\
\hline 2050 & 23.5 & 27.5 & 31 & 38.2 & 30.6 & 29.6 & 24.6 & 25.4 \\
\hline $\begin{array}{l}\text { Sex ratio, } 60+\text { years (men per } 100 \\
\text { women) }(2009)^{2}\end{array}$ & 72 & 69 & 67 & 91 & 79 & 80 & 87 & 82 \\
\hline Urban population (\%) $(2000)^{3}$ & 89.1 & 92.0 & 33.8 & 75.3 & 86.1 & 81.2 & 74.7 & 75.3 \\
\hline $\begin{array}{l}\text { Population in main metropolitan areas } \\
\quad(\%)(2000)^{4}\end{array}$ & 33.2 & 47.4 & 50.7 & 19.7 & 35.7 & 10.1 & 18.0 & NA \\
\hline \multicolumn{9}{|l|}{ Socio-economic indicators: } \\
\hline $\begin{array}{l}\text { GDP per capita (constant } 2010 \text { US } \$ \text { ) } \\
(2000)^{5}\end{array}$ & 8,183 & 8,998 & 14,967 & 3,473 & 9,469 & 8,778 & 8,660 & 7,387 \\
\hline Pension coverage $(2000-2005)^{6}$ & 68.3 & 87.1 & $92^{7}$ & NA & 76 & 85.9 & 19.2 & \\
\hline
\end{tabular}

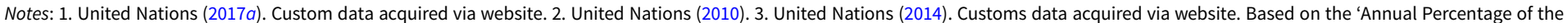
Population at Mid-year Residing in Urban Areas'. 4. Economic Commission for Latin America and the Caribbean (2010). Main metropolitan areas: Buenos Aires, Montevideo, Bridgetown, Havana, Santiago, São Paulo and Mexico City. 5. World Bank (2017). 6. Mesa-Lago (2009). 7. Pettinato and Cassou (2005). GDP: Gross Domestic Product. NA: not available. 
(69 years) (UN, 2017a). Gender differences in life expectancy at birth and at age 60 are also noted across the region, with the widest gaps in the sex ratio at age 60 reported in Barbados, Uruguay and Argentina.

Declining fertility rates and longer life expectancy suggest that current and future older adults in the region can experience longer lives with fewer sources of family support, particularly children. The reported prevalence of biological childlessness, based on census data, among women 60 years and older mirrors the countries' pace of demographic transition: 13 per cent in Argentina (2001), 11.2 per cent in Brazil (2000), 13 per cent in Chile (2000) and 9.5 per cent in Mexico (2000) (De Vos, 2014). Based on estimates from the 2000 SABE, the prevalence of urban older adults with no living children ranges from 5.2 per cent in Mexico City to 13 per cent in Bridgetown.

Differences in the pace of demographic transition also contribute to crossnational variation in the living arrangements of older adults. Generally, multigenerational households are a common feature of Latin American and Caribbean societies (UN, 2005). In advanced transition countries such as Argentina, Uruguay and Barbados, however, older adults live, on average, in smaller households with approximately two or three other persons. In less-advanced ageing countries, older adults live in households with approximately four persons (Nam, 2009; Cotlear, 2011). Gendered patterns are evident such that women are more likely than men to live in multigenerational households while men are more likely to live alone (Cotlear and Tornarolli, 2011). These living arrangements are particularly common among childless older Latin American women where over a third live with others: Argentina (36.6\%), Brazil (38.1\%), Chile (40.8\%) and Mexico (45.2\%) (De Vos, 2014). While solo living is positively associated with higher depressive symptoms (Ylli et al., 2016), multigenerational living arrangements have been shown to protect against late-life depression among older adults in Havana, Cuba (Sicotte et al., 2008).

Furthermore, across the region there are important differences in terms of economic wellbeing and the accountability of the state, market and family for the welfare of older adults. These differences, especially with regard to income security, may influence the intensity of older adults' reliance on family members, and the mental health implications of not having a spouse or children. Data from the World Development Indicators published by the World Bank, shown in Table 1, indicate that the GDP per capita in 2000 (constant 2010 US \$) varied widely. While GDP per capita was US $\$ 3,473$ in Cuba it reached almost US $\$ 15,000$ in Barbados, with other countries falling in between. Differences in levels of economic development, based on GDP per capita, contribute to cross-national differences in systems of formal support, such as pension and public health-care coverage. As shown in Table 1, Argentina, Uruguay, Brazil, Barbados and Chile show relatively stronger systems of income security, based on higher social security coverage, while Mexico has a weaker social security system. Nonetheless, these systems tended to cover those who had contributed, mostly men in the formal labour market, with many women not covered. Women in some countries such as Mexico, Brazil, Argentina and Chile have higher coverage due to social pensions and/or extended coverage of widowers' pensions (Parker and Wong, 2001; Bertranou, 2006). 
These national estimates correspond to the data collected among older adults in urban areas of the current study. According to data from the 2000 SABE, there are marked differences across sites in pension coverage and levels of income sufficiency. For instance, only 32 per cent of older adults in Mexico City reported receiving pensions, with this percentage increasing in Buenos Aires (66\%), Bridgetown (69\%), São Paulo (73\%), Montevideo (81\%) and Santiago (99\%). Even though every older adult reported receiving a pension in Havana, only 21 per cent reported having enough money to live on, the lowest percentage across sites: São Paulo (31\%), Santiago (32\%), Buenos Aires (34\%), Bridgetown (37\%), Montevideo (42\%) and Mexico City (52\%).

Thus, pension coverage does not necessarily translate into income sufficiency. Even in countries with high levels of pension coverage, near 30-40 per cent of older adults in the urban centres perceive that their income is inadequate to sustain their daily living. The wide discrepancy between pension coverage and subjective income sufficiency among older adults in Havana, Cuba can be attributed to Cuba's economic crisis following the collapse of the Soviet Union in 1990, which positioned older adults among the most vulnerable groups due to a combination of reduced pensions and currency devaluation that imposed further limits on the purchasing power of their income (Brundenius, 2002; Mesa-Lago, 2005).

Alongside the demographic transition, Latin American and Caribbean countries are undergoing an epidemiological transition and currently face a high prevalence of chronic non-communicable diseases in adulthood. According to analyses of SABE survey data collected from older adults in seven cities within the regions, approximately 77 per cent of older adults in these urban areas have at least one chronic disease, nearly 45 per cent experience comorbidities and about 20 per cent experience disabilities (Medici, 2011). Chronic diseases and disability place high demands on care and support arrangements. Formal health-care services range from near universal coverage in Barbados, Cuba and Brazil to markedly unequal in Mexico (Haggard and Kaufman, 2008; Atun et al., 2015). Access to long-term care facilities for older adults in Latin American countries depends on one's access to social or health insurance, whilst in the Caribbean there are more home care services provided by the state (Huenchuan, 2013). Although older adults may not rely on or expect children to provide health-related support, informal support from adult children may be especially important for older adults with debilitating health needs, especially those who may not have access to or the ability to afford reliable health services.

In sum, social norms in Latin America and the Caribbean point to the importance of familial resources for material, instrumental and emotional support to older adults. Therefore, it is important to examine the salience of the availability of children and spouses, the common sources of informal support, to the mental health of older adults; the circumstances under which parental and marital status may be more or less relevant to mental health; and, finally, the relative importance of the unavailability of spouses and children to older adults' likelihood of experiencing depressive symptoms across different demographic, institutional and economic contexts within the region. This paper addresses this gap in the literature.

Our study has four hypotheses. First, we hypothesise that parents will be less likely to experience depressive symptoms relative to childless older adults 
(Hypothesis 1). Second, we expect that unmarried older adults will experience more depressive symptoms relative to married older adults (Hypothesis 2). Our third hypothesis examines the indirect effect of familial resources on mental health and is divided into two parts. Hypothesis 3 a proposes that the difference in depressive symptoms experienced by childless older adults relative to parents will be greater among those who have inadequate income compared to those with adequate. Similarly regarding marital status, Hypothesis $3 \mathrm{~b}$ proposes that the difference in depressive symptoms experienced between married and unmarried older adults will be greater among older adults with inadequate income relative to those who perceive income adequacy. Last, we test whether the association between parental status and marital status, respectively, and depression varies across contexts (Hypothesis 4).

\section{Methods}

\section{Sample}

Data on self-reported depression prevalence in seven major cities in Latin America and the Caribbean come from SABE. This multi-centre project surveyed the health and wellbeing of older individuals (60 or more years of age), and in some cases, of the surviving spouse, in seven capital/major cities: Buenos Aires, Argentina; Bridgetown, Barbados; São Paulo, Brazil; Santiago, Chile; Havana, Cuba; Mexico City, Mexico; and Montevideo, Uruguay. A standardised questionnaire was used to collect detailed information through face-to-face interviews. Samples were drawn using multi-stage clustered sampling with stratification of the units at the highest levels of aggregation. Detailed information on sample selection has been presented elsewhere (Wong et al., 2006).

The initial sample consisted of 10,597 individuals who were aged 60 years or older. Of this sample, 841 (7.9\%) responses had missing data on selected study variables, mostly depression, education and economic security. Compared to those with complete data, individuals who had missing data were older (70 versus 75 years of age, $p<0.001)$ and were more likely to have limitations on activities of daily living (ADLs) $(p<0.001)$. However, we found no differences either in the number of children alive or in gender. The final analytic sample consisted of 9,756 individuals.

\section{Measures}

\section{Depressive symptoms}

The dependent variable, depressive symptoms, was assessed using the GDS-15, a 15-item version of the Yesavage Geriatric Depression Scale (Yesavage et al., 1983). The short-form GDS is considered appropriate for the purpose of depression screening among community-dwelling older adults because it is simple to complete and rate (Almeida and Almeida, 1999). Scores range from 0 to 15. We chose a cutoff point of $4 / 5$ based on existing empirical studies examining the utility of the GDS among older adults with different levels of cognition (Yesavage and Sheikh, 1986; Burke et al., 1991). Persons scoring 0-4 were categorised as having no depressive symptoms, and those scoring 5 or above as having depressive symptoms. Five missing answers were allowed and final scores were pro-rated. Those with more than 
five missing answers were excluded from the present study $(\mathrm{N}=487)$, unless their score was 5 or more, which would classify them as having depressive symptoms $(\mathrm{N}=37)$. The alpha coefficient of reliability using Kuder-Richardson's formula was 0.84 (male: 0.80 , female: 0.85 ).

\section{Parental status}

Respondents were asked to indicate the number of children (biological or not) who were still alive. The responses were dichotomously coded as childless (no living children) and one or more children.

\section{Marital status and living arrangements}

Marital status (married and unmarried) was combined with living arrangements (alone and living with others) since most people who reported being married (formally or in consensual unions) also reported living with someone. Three categories were created: married, living alone, unmarried and living alone, and unmarried and living with others, which includes kin and non-kin.

Covariates: Socio-demographic covariates included age, gender, income adequacy and educational attainment. Age in years was coded as a categorical indicator with those aged 70-79 years as the reference group, compared to those 60-89, and 80 or more years. Respondents' gender was measured dichotomously with men as the reference group. Older adults' perceived economic adequacy was based on their response to a question asking if they had enough money to live on. We coded as a binary measure with those indicating no, they did not have enough money, as the reference group. Educational attainment was based on years of completed education aggregated into four categories: no schooling, primary schooling (reference category), high school and more than high school education.

Indicators of health status included chronic conditions and ADL impairment. The number of self-reported chronic conditions with prior diagnosis (hypertension, diabetes, cancer, lung disease, heart attack, stroke and arthritis) had three categories: no conditions (reference category), one condition, and two or more conditions. The measure of ADL impairment was based on activities that participants reported having difficulty in performing: dressing, bathing, eating, getting in and out of a bed (transferring), toileting, and getting across a room. We dichotomised the ADL measure: a score of 0 indicated that the respondent did not have any disability and a score of 1 indicated that the respondent had difficulty performing at least one activity. Finally, the city of residence was included as a control for contextual resources. São Paulo was chosen as the reference city.

\section{Statistical analysis}

Descriptive statistics reflect the prevalence of depressive symptoms among older adults in the sample and the distributions of individuals' characteristics across the cities (Table 2). Table 3 presents the prevalence of depressive symptoms by sex and parental status, and explores the bivariate associations between having children and depressive symptoms in the pooled data, by sex and for each city. We compared the categorical variables using Pearson's chi-square corrected for the survey design with the second-order correction of Rao and Scott (1984). 
Table 2. Percentage distribution of sample characteristics of older adults in Latin American and Caribbean cities

\begin{tabular}{|c|c|c|c|c|c|c|c|c|c|}
\hline Characteristics of older adults & Pooled & Bridgetown & $\begin{array}{l}\text { Buenos } \\
\text { Aires }\end{array}$ & $\begin{array}{l}\text { Mexico } \\
\text { City }\end{array}$ & Havana & Montevideo & Santiago & $\begin{array}{l}\text { São } \\
\text { Paulo }\end{array}$ & $p$ \\
\hline Depressive symptoms: ${ }^{1}$ & & & & & & & & & $<0.0001$ \\
\hline No & 74.5 & 90.9 & 79.4 & 73.8 & 75.2 & 73.5 & 63.2 & 72.6 & \\
\hline Yes & 25.5 & 9.1 & 20.6 & 26.2 & 24.8 & 26.5 & 36.8 & 27.4 & \\
\hline Parental status: & & & & & & & & & $<0.0001$ \\
\hline Childless & 8.6 & 13.1 & 11.5 & 4.4 & 10.6 & 8.7 & 7.3 & 8.9 & \\
\hline At least one child & 91.4 & 86.9 & 88.5 & 95.6 & 89.4 & 91.3 & 92.7 & 91.1 & \\
\hline Gender: & & & & & & & & & 0.0061 \\
\hline Men & 40.2 & 39.2 & 37.8 & 44.0 & 40.7 & 36.0 & 39.8 & 41.6 & \\
\hline Women & 59.8 & 60.8 & 62.2 & 56.0 & 59.3 & 64.1 & 60.2 & 58.4 & \\
\hline Income adequacy: & & & & & & & & & $<0.0001$ \\
\hline No & 62.7 & 63.1 & 66.1 & 48.9 & 78.9 & 58.0 & 68.2 & 67.8 & \\
\hline Yes & 37.3 & 36.9 & 33.9 & 51.1 & 21.1 & 42.0 & 31.8 & 32.2 & \\
\hline $\begin{array}{l}\text { Marital status and living } \\
\text { arrangement: }\end{array}$ & & & & & & & & & $<0.0001$ \\
\hline Married & 55.0 & 35.5 & 56.0 & 56.5 & 40.1 & 49.0 & 57.2 & 59.2 & \\
\hline Unmarried, living alone & 16.9 & 24.0 & 19.6 & 9.9 & 10.5 & 17.6 & 33.7 & 13.0 & \\
\hline Unmarried, living with others & 28.1 & 40.4 & 24.3 & 33.6 & 49.4 & 33.4 & 9.2 & 27.8 & \\
\hline Age groups: & & & & & & & & & $<0.0001$ \\
\hline $60-69$ & 53.7 & 41.9 & 49.1 & 58.0 & 50.4 & 46.8 & 53.7 & 62.2 & \\
\hline $70-79$ & 35.0 & 37.2 & 40.1 & 30.8 & 32.8 & 39.8 & 33.3 & 30.0 & \\
\hline $80+$ & 11.3 & 20.9 & 10.8 & 11.2 & 16.8 & 13.4 & 13.0 & 7.8 & \\
\hline
\end{tabular}




\begin{tabular}{|c|c|c|c|c|c|c|c|c|c|}
\hline Educational categories: & & & & & & & & & $<0.0001$ \\
\hline None & 13.8 & 2.5 & 5.4 & 24.4 & 4.6 & 6.3 & 15.2 & 23.0 & \\
\hline Primary & 60.9 & 77.4 & 64.3 & 54.9 & 54.8 & 67.4 & 53.6 & 66.7 & \\
\hline More than high school & 8.8 & 4.8 & 11.0 & 7.4 & 7.4 & 10.1 & 10.0 & 5.3 & \\
\hline \multicolumn{10}{|l|}{ Disability: } \\
\hline Number of chronic conditions: & & & & & & & & & $<0.0001$ \\
\hline None & 23.6 & 24.5 & 18.8 & 31.9 & 19.8 & 22.2 & 22.5 & 24.5 & \\
\hline One & 33.4 & 31.0 & 35.5 & 33.9 & 30.2 & 31.1 & 33.7 & 30.9 & \\
\hline Two or more & 43.0 & 44.5 & 45.7 & 34.2 & 50.1 & 46.7 & 43.7 & 44.7 & \\
\hline
\end{tabular}

Note: 1. Based on the short-form Geriatric Depression Scale (GDS-15). Persons scoring 0-4 were categorised as having no depressive symptoms, and those scoring 5 or above as having depressive symptoms.

Source: Survey of Health, Well-being and Aging in Latin America and the Caribbean (2000 SABE). 


\begin{tabular}{|c|c|c|c|c|c|c|c|c|}
\hline Characteristics of older adults & Pooled & Bridgetown & Buenos Aires & Mexico City & Havana & Montevideo & Santiago & São Paulo \\
\hline \multicolumn{9}{|l|}{ Total: } \\
\hline Childless & 30.4 & 10.7 & 28.0 & 27.0 & 33.0 & 27.7 & 55.6 & 26.0 \\
\hline At least one child & 25.1 & 8.9 & 19.7 & 26.2 & 23.8 & 26.4 & 35.3 & 27.6 \\
\hline$P$ & 0.0221 & 0.4249 & 0.0463 & 0.9011 & 0.0057 & 0.7746 & 0.0022 & 0.6912 \\
\hline \multicolumn{9}{|l|}{ Females: } \\
\hline Childless & 32.9 & 7.1 & 33.5 & 26.1 & 36.9 & 20.8 & 51.8 & 30.3 \\
\hline At least one child & 27.9 & 9.0 & 20.2 & 30.3 & 29.8 & 31.4 & 38.1 & 31.3 \\
\hline$P$ & 0.0919 & 0.5081 & 0.0110 & 0.5716 & 0.0970 & 0.0739 & 0.0816 & 0.8427 \\
\hline \multicolumn{9}{|l|}{ Males: } \\
\hline Childless & 25.2 & 19.6 & 16.3 & 29.4 & 24.3 & 41.6 & 63.3 & 18.3 \\
\hline At least one child & 20.9 & 8.8 & 18.8 & 21.1 & 15.4 & 17.5 & 31.2 & 22.5 \\
\hline$P$ & 0.2677 & 0.0136 & 0.7314 & 0.4678 & 0.0911 & 0.0007 & 0.0057 & 0.5206 \\
\hline
\end{tabular}

Note: 1. Based on the short-form Geriatric Depression Scale (GDS-15). Persons scoring 0-4 were categorised as having no depressive symptoms, and those scoring 5 or above as having depressive symptoms.

Source: Survey of Health, Well-being and Aging in Latin America and the Caribbean (2000 SABE). 
Multivariate logistic regression analyses were used to test the study hypotheses. These results are presented in Table 4 . Based on pooled data for all cities, the first set of multivariate analyses examines the direct effect and indirect or stressbuffering effect of family resources on older adults' mental health. These estimates are presented in Table 4. Models 1 and 2 examined the direct effect of the relationship between parental status, marital status and depression which test Hypotheses 1 and 2. Next, Models 3 and 4 tested whether income adequacy modifies the association between each of parental status and marital status on depression (Hypothesis 3). To facilitate easier interpretation of the interaction terms we estimated predicted probabilities using the margins command. Finally, Table 5 presents the results of the moderating effect of city of residence on the relationship between parental status and marital status, respectively, and depression (Hypothesis 4). All results shown are weighted, taking into account the complex sampling design. Significance level was set to 0.05 .

\section{Results}

\section{Descriptive results}

Table 2 shows the prevalence of depressive symptoms, and the demographic, social and health characteristics of the sample. About one-quarter of the older adult population in these urban areas had depressive symptoms, with the lowest prevalence in Bridgetown (9.1\%) and the highest in Santiago (36.8\%). Only a small percentage of older adults did not have a living child (8.6\%). Mexico City showed the lowest percentage of childless older adults (4.4\%), while Bridgetown had the highest (13.1\%). In the pooled sample, most participants were married (55\%), but with important differences across settings. The lowest percentage of married older adults was found in Bridgetown (35.5\%) and the highest in São Paulo (59.2\%). Income adequacy or sufficiency was limited to only 37.2 per cent of the sample, but differences across cities were statistically significant. The majority of the sample was aged 60-69 years, female, completed primary education, did not have disabilities and had at least one chronic condition.

Table 3 shows the prevalence of depressive symptoms according to older adults' parental status and city of residence. In the pooled sample, childless older adults were more likely to report depressive symptoms than those with children $(30.4 \%$ versus 25.1\%, respectively, $p=0.0221$ ). In Buenos Aires, Havana and Santiago, childless older adults had higher prevalence rates of depressive symptoms than those with children. We found no statistically significant differences according to parental status in Bridgetown, Mexico City, Montevideo and São Paulo. In analyses stratified by sex, prevalence rates of depressive symptoms were higher among childless women in Buenos Aires than among their counterparts with children. Among men, prevalence rates of depressive symptoms were higher among those without children than among those with children in Bridgetown, Montevideo and Santiago.

\section{Multivariate results}

Table 4 presents the results of the multivariate logistic regression analyses which test our first three hypotheses. Hypothesis 1 proposed that parents would be less 
Table 4. Logistic regression odds ratios (OR) for depressive symptoms ${ }^{1}$

\begin{tabular}{|c|c|c|c|c|c|c|c|c|}
\hline \multirow[b]{2}{*}{ Characteristics of older adults } & \multicolumn{2}{|c|}{ Model 1} & \multicolumn{2}{|c|}{ Model 2} & \multicolumn{2}{|c|}{ Model 3} & \multicolumn{2}{|c|}{ Model 4} \\
\hline & OR & $95 \% \mathrm{Cl}$ & OR & $95 \% \mathrm{Cl}$ & OR & $95 \% \mathrm{Cl}$ & OR & $95 \% \mathrm{Cl}$ \\
\hline \multicolumn{9}{|l|}{ Parental status (Ref. Childless): } \\
\hline At least one child & $0.72^{\star \star}$ & $0.58,0.91$ & 0.80 & $0.62,1.02$ & 0.83 & $0.62,1.12$ & 0.79 & $0.62,1.02$ \\
\hline \multicolumn{9}{|l|}{ City (Ref. São Paulo): } \\
\hline Bridgetown & $0.26^{\star \star \star}$ & $0.21,0.33$ & $0.25^{\star \star \star}$ & $0.20,0.32$ & $0.25^{\star \star \star}$ & $0.20,0.32$ & $0.26^{\star \star \star}$ & $0.20,0.32$ \\
\hline Buenos Aires & $0.68^{\star \star}$ & $0.56,0.83$ & $0.69^{\star \star}$ & $0.55,0.85$ & $0.69^{\star \star \star}$ & $0.55,0.85$ & $0.69^{\star \star \star}$ & $0.56,0.86$ \\
\hline Mexico City & 0.96 & $0.80,1.14$ & 1.12 & $0.92,1.36$ & 1.12 & $0.92,1.36$ & 1.12 & $0.92,1.36$ \\
\hline Havana & 0.86 & $0.74,1.02$ & $0.78^{\star \star}$ & $0.64,0.94$ & $0.78^{\star \star}$ & $0.64,0.94$ & $0.79^{\star}$ & $0.65,0.96$ \\
\hline Montevideo & 0.95 & $0.80,1.14$ & 1.02 & $0.84,1.24$ & 1.02 & $0.84,1.25$ & 1.03 & $0.85,1.25$ \\
\hline Santiago & $1.55^{\star \star \star}$ & $1.27,1.88$ & $1.54^{\star \star \star}$ & $1.24,1.91$ & $1.55^{\star \star \star}$ & $1.24,1.92$ & $1.55^{\star \star \star}$ & $1.25,1.93$ \\
\hline \multicolumn{9}{|c|}{$\begin{array}{l}\text { Marital status and living arrangement } \\
\text { (Ref. Married): }\end{array}$} \\
\hline Unmarried, living alone & & & $1.64^{\star \star \star}$ & $1.35,2.00$ & $1.64^{\star \star \star}$ & $1.35,2.00$ & $1.46^{\star \star \star}$ & $1.16,183$ \\
\hline Unmarried, living with others & & & $1.42^{\star \star \star}$ & $1.20,1.70$ & $1.42^{\star \star \star}$ & $1.20,1.70$ & 1.22 & $0.99,1.49$ \\
\hline \multicolumn{9}{|l|}{ Age groups (Ref. $70-79$ years): } \\
\hline $60-69$ & & & 1.12 & $0.96,1.31$ & 1.12 & $0.96,1.31$ & 1.13 & $0.96,1.32$ \\
\hline $80+$ & & & 0.85 & $0.67,1.08$ & 0.85 & $0.67,1.08$ & 0.85 & $0.67,1.08$ \\
\hline \multicolumn{9}{|l|}{ Gender (Ref. Men): } \\
\hline Women & & & 1.06 & $0.90,1.24$ & 1.05 & $0.90,1.24$ & 1.06 & $0.90,1.24$ \\
\hline
\end{tabular}


Education (Ref. Primary schooling):

\begin{tabular}{|c|c|c|c|c|c|c|c|}
\hline None & & $1.27^{\star \star}$ & $1.05,1.54$ & $1.27^{\star \star}$ & $1.05,1.53$ & $1.28^{\star \star}$ & $1.06,1.55$ \\
\hline High school & & 0.87 & $0.70,1.08$ & 0.86 & $0.70,1.07$ & 0.87 & $0.70,1.07$ \\
\hline More than high school & & 0.81 & $0.60,1.08$ & 0.81 & $0.60,1.08$ & 0.83 & $0.62,1.12$ \\
\hline \multicolumn{8}{|l|}{ Income adequacy (Ref. Not enough money): } \\
\hline Yes, enough money & & $0.49^{\star \star \star}$ & $0.42,0.57$ & $0.57^{\star}$ & $0.34,0.96$ & $0.37^{\star \star \star}$ & $0.27,0.47$ \\
\hline \multicolumn{8}{|l|}{ Disability (Ref. No difficulties): } \\
\hline At least one difficulty & & $3.59^{\star \star \star}$ & $3.03,4.25$ & $3.59^{\star \star \star}$ & $3.03,4.25$ & $3.58^{\star \star \star}$ & $3.02,4.23$ \\
\hline \multicolumn{8}{|l|}{ Number of chronic conditions (Ref. None): } \\
\hline One & & $1.37^{\star \star}$ & $1.12,1.68$ & $1.37^{\star \star}$ & $1.12,1.68$ & $1.37^{\star \star}$ & $1.12,1.68$ \\
\hline Two or more & & $1.99^{\star \star \star}$ & $1.64,2.42$ & $1.99^{\star \star \star}$ & $1.64,2.42$ & $1.99^{\star \star \star}$ & $1.64,2.42$ \\
\hline \multicolumn{8}{|l|}{ Parental status $\times$ Income adequacy } \\
\hline At least one child $\times$ Yes, enough money & & & & 0.84 & $0.49,1.47$ & & \\
\hline \multicolumn{8}{|l|}{ Marital status $\times$ Income adequacy } \\
\hline Unmarried, alone $\times$ Yes, enough money & & & & & & $1.54^{\star}$ & $1.04,2.26$ \\
\hline Unmarried, with others $\times$ Yes, enough money & & & & & & $1.75^{\star \star}$ & $1.24,2.49$ \\
\hline Constant & $0.40,0.64$ & $0.21^{\star \star \star}$ & $0.15,0.30$ & $0.20^{\star \star \star}$ & $0.14,0.29$ & $0.23^{\star \star \star}$ & $0.16,0.32$ \\
\hline F-statistic & $33.05^{\star \star \star}$ & \multicolumn{2}{|c|}{$36.03^{\star \star \star}$} & \multicolumn{2}{|c|}{$34.56^{\star \star \star}$} & \multicolumn{2}{|c|}{$32.65^{\star \star \star}$} \\
\hline $\mathrm{N}$ & 9,756 & \multicolumn{2}{|c|}{9,756} & \multicolumn{2}{|c|}{9,756} & \multicolumn{2}{|c|}{9,756} \\
\hline
\end{tabular}

Notes: 1. Based on the short-form Geriatric Depression Scale (GDS-15). Cl: confidence interval. Ref.: reference category.

Source: Survey of Health, Well-being and Aging in Latin America and the Caribbean (2000 SABE).

Significance levels: ${ }^{\star} p<0.05,{ }^{\star \star} p<0.01,{ }^{\star * \star} p<0.001$. 
vulnerable to depressive symptoms compared to childless older adults. Results presented in Model 1 indicate that having at least one child was a protective factor for older adults in these urban areas in Latin America and the Caribbean. However, upon adjusting for individual socio-demographic, economic and health factors (Model 2), the coefficient for parental status was no longer statistically significant. Hypothesis 2 proposed that unmarried older adults would be more vulnerable to depression compared to their married counterparts. The results from Model 2 support this hypothesis as those who were unmarried, regardless of their living arrangement, were more likely than married older adults to report depressive symptoms. Results from Model 2 also point to statistically significant differences in the depressive symptoms across cities. Compared to older adults in São Paulo, those in Bridgetown, Buenos Aires and Havana were less likely to report having depressive symptoms, whereas those in Santiago were more likely. Gender differences in depressive symptoms were not evident, but those with adequate income were less likely to report having depressive symptoms.

Next, we explored whether perceived income adequacy modified the effect of both parental and marital status on depressive symptoms. Hypothesis 3a proposed that the difference in depressive symptoms between childless and parents would be higher among older adults with inadequate income compared to those who perceived their income as adequate. Likewise, Hypothesis $3 \mathrm{~b}$ proposed that the association between marital status and depressive symptoms will be stronger among those with inadequate income compared to those with adequate income. Findings presented in Model 3 indicate that perceived income adequacy did not moderate the association between parental status and depressive symptoms. Model 4, however, shows that perceived income adequacy moderates the relationship between marital status and depressive symptoms, thereby providing support for Hypothesis $3 \mathrm{~b}$. To better interpret the differences in depressive symptoms experienced according to marital status and perceived income adequacy, we present the predicted probabilities in Figure 1. The results show that unmarried older adults who perceived their income as inadequate showed greater vulnerability to experiencing depressive symptoms than their married counterparts. Unmarried older adults living alone who experienced financial strain were the most vulnerable.

Finally, we explored whether city of residence modified the association between parental status and depressive symptoms. Our results, presented in Table 5, did not show any significant systematic differences across cities in the importance of parenthood to later-life depression (Model 5). We found support for geographic differences in the relationship between marital status and depression whereby the psychological disadvantage of being unmarried was pertinent to older adults in Havana and Montevideo (Model 6). Figure 2 shows the predicted probabilities of the interaction of marital status and city of residence. Unmarried older adults living alone in Havana and unmarried older adults living with others in Montevideo were more disadvantaged than their married counterparts.

\section{Discussion}

This paper explored whether parental status and marital status are associated with depressive symptoms among older adults in seven cities in Latin America and the 


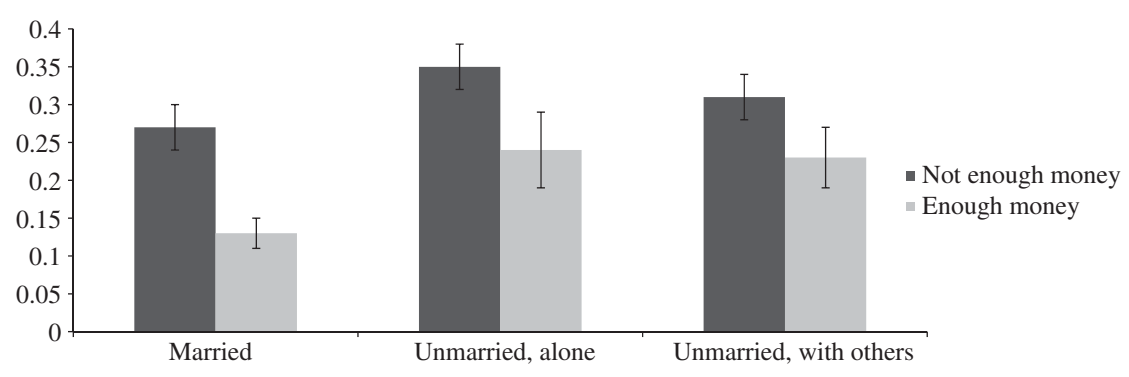

Figure 1. Predicted probabilities of depression according to marital status and perceived income adequacy with 95 per cent confidence intervals.

Caribbean. Our results indicated that older adults with no children did not differ from those with at least one child in experiencing elevated depressive symptoms, after controlling for demographic, social and economic variables. Our results, however, provide support for the importance of marital status to older adults' psychological wellbeing.

Although the finding that parental status was not associated with elevated depressive symptoms differs from most of the existing research in other developing countries such as China, where children are an important resource for older adults' wellbeing and childless older adults generally experience worse psychological wellbeing than those with children (Chou and Chi, 2004; Zhang and Liu, 2007; Guo, 2014), there is partial correspondence with some recent research which shows that childless older adults in urban areas do not experience any significant difference in depression compared to parents living in rural areas (Djundeva et al., 2017). On one hand, our findings may suggest that the presence of children is less salient to the mental health of older adults in these urban areas of Latin America and the Caribbean at the beginning of the 21st century. On the other hand, we examined only the availability of children as a potential source of social support rather the functional aspects of social support such as intergenerational support or the quality of relationships, which are also important to older adults' psychological wellbeing (Buber and Engelhardt, 2008; Schwarzbach et al., 2014). Nevertheless, as fertility rates are projected to continue a downward trend and life expectancy to increase, future cohorts of older adults will likely live longer lives with fewer or no children available as a source of support. Although, the complete set of social and economic implications of childlessness in Latin America and the Caribbean are unknown, our study provides a step in exploring the role of children in this context.

We find evidence of a protective effect of marriage for older adults' mental health as unmarried older adults, those living alone and those living with others were more likely to experience elevated depressive symptoms than their married counterparts. Therefore, aligned with existing research (Koropeckyj-Cox, 1998; Zhang and Hayward, 2001; Hank and Wagner, 2013), marital status seems more salient than parental status to older adults' mental health in urban Latin America and the Caribbean. That unmarried older adults, regardless of their living arrangements, were more vulnerable to experiencing elevated depressive symptoms 
Table 5. Logistic regression odds ratios (OR) for depression ${ }^{1}$ showing main and interaction effects of parental status, marital status and city of residence

\begin{tabular}{|c|c|c|c|c|}
\hline \multirow[b]{2}{*}{ Characteristics of older adults } & \multicolumn{2}{|c|}{ Model 5} & \multicolumn{2}{|c|}{ Model 6} \\
\hline & OR & $95 \% \mathrm{Cl}$ & OR & $95 \% \mathrm{Cl}$ \\
\hline \multicolumn{5}{|l|}{ Parental status (Ref. Childless): } \\
\hline At least one child & 1.05 & $0.67,1.65$ & 0.81 & $0.63,1.04$ \\
\hline \multicolumn{5}{|l|}{ City (Ref. São Paulo): } \\
\hline Bridgetown & $0.29^{\star \star \star}$ & $0.15,0.56$ & $0.28^{\star \star \star}$ & $0.19,0.41$ \\
\hline Buenos Aires & 0.97 & $0.51,1.80$ & $0.58^{\star \star}$ & $0.42,0.82$ \\
\hline Mexico City & 1.04 & $0.47,2.26$ & $1.29^{*}$ & $1.00,1.68$ \\
\hline Havana & 1.23 & $0.72,2.10$ & $0.67^{\star *}$ & $0.50,0.90$ \\
\hline Montevideo & 1.1 & $0.57,2.10$ & 0.81 & $0.61,1.08$ \\
\hline Santiago & $2.82^{\star \star \star}$ & $1.46,5.44$ & $1.53^{\star \star}$ & $1.13,2.07$ \\
\hline
\end{tabular}

Marital status and living arrangement

(Ref. Married):

$\begin{array}{lllll}\text { Unmarried, living alone } & 1.63^{\star \star \star} & 1.34,1.99 & 1.33 & 0.90,1.97 \\ \text { Unmarried, living with others } & 1.43^{\star \star \star} & 1.20,1.70 & 1.41^{*} & 1.06,1.88\end{array}$

Parental status $\times$ City:

\begin{tabular}{lcc} 
At least one child $\times$ Bridgetown & 0.87 & $0.43,1.79$ \\
At least one child $\times$ Buenos Aires & 0.68 & $0.35,1.33$ \\
\hline At least one child $\times$ Mexico City & 1.07 & $0.48,2.39$ \\
At least one child $\times$ Havana & 0.60 & $0.34,1.05$ \\
At least one child $\times$ Montevideo & 0.93 & $0.47,1.83$ \\
At least one child $\times$ Santiago & 0.52 & $0.26,1.03$
\end{tabular}

Marital status $\times$ City:

\begin{tabular}{lcc} 
Unmarried alone $\times$ Bridgetown & 1.12 & $0.59,2.12$ \\
Unmarried alone $\times$ Buenos Aires & 1.54 & $0.88,2.70$ \\
Unmarried alone $\times$ Mexico City & 0.83 & $0.46,1.49$ \\
\hline Unmarried alone $\times$ Havana & $2.35^{\star *}$ & $1.37,4.04$ \\
Unmarried alone $\times$ Montevideo & 1.42 & $0.82,2.47$ \\
Unmarried alone $\times$ Santiago & 1.18 & $0.71,1.97$ \\
Marital status $\times$ City: & & \\
Unmarried with others $\times$ Bridgetown & 0.80 & $0.47,1.38$ \\
Unmarried with others $\times$ Buenos Aires & 1.29 & $0.79,2.12$ \\
Unmarried with others $\times$ Mexico City & 0.69 & $0.46,1.05$ \\
Unmarried with others $\times$ Havana & 1.07 & $0.73,1.59$ \\
\hline
\end{tabular}

(Continued) 
Table 5. (Continued.)

\begin{tabular}{|c|c|c|c|c|}
\hline \multirow[b]{2}{*}{ Characteristics of older adults } & \multicolumn{2}{|c|}{ Model 5} & \multicolumn{2}{|c|}{ Model 6} \\
\hline & OR & $95 \% \mathrm{Cl}$ & OR & $95 \% \mathrm{Cl}$ \\
\hline Unmarried with others $\times$ Montevideo & & & $1.58^{\star}$ & $1.03,2.42$ \\
\hline Unmarried with others $\times$ Santiago & & & 0.94 & $0.53,1.66$ \\
\hline Constant & $0.17^{\star \star \star}$ & $0.10,0.27$ & $0.22^{\star \star \star}$ & $0.15,0.31$ \\
\hline F-statistic & \multicolumn{2}{|c|}{$27.96^{\star \star \star}$} & \multicolumn{2}{|c|}{$23.76^{\star \star \star}$} \\
\hline $\mathrm{N}$ & \multicolumn{2}{|c|}{9,756} & \multicolumn{2}{|c|}{9,756} \\
\hline
\end{tabular}

Notes: Models control for age, gender, educational attainment, income adequacy, disability and chronic conditions. 1. Based on the short-form Geriatric Depression Scale. $\mathrm{Cl}$ : confidence interval.

Source: Survey of Health, Well-being and Aging in Latin America and the Caribbean (2000 SABE).

Significance levels: ${ }^{\star} p<0.05,{ }^{\star \star} p<0.01,{ }^{\star \star \star} p<0.001$.

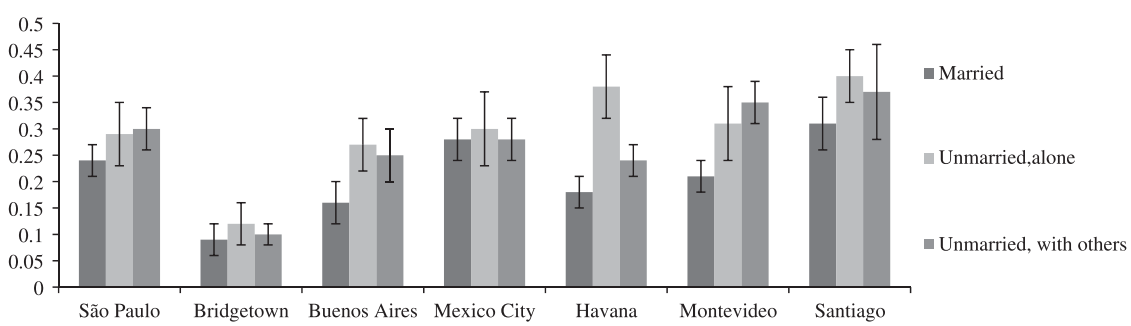

Figure 2. Predicted probabilities of depressive symptoms according to marital status and city of residence with 95 per cent confidence intervals

reinforces existing research that marital relationships are among the most influential social ties, and the availability of a spouse/partner affects individual wellbeing, throughout adulthood (Thomas et al., 2017).

The loss of a spouse or partner is a major stressful life event that diminishes wellbeing, but being unmarried and living within households with limited or unfulfilling social support may further increase one's vulnerability to mental health declines. Although multigenerational living arrangements are commonplace within the region, and the availability of these social networks has been shown to be protective for older adults' depression (Sicotte et al., 2008), household composition and the quality of relationships among members may define older adults' health outcomes. Studies have shown that older adults' experiences of negative or ambivalent interactions typically occur with family members or friends, and negative relations with these sources can be more detrimental to older adults' wellbeing than positive social relations (Rook, 2015). Thus, closer examination of the intersections of marital status, living arrangements and household relationships with later-life mental health needs to be included in future research within Latin America and the Caribbean.

This is buttressed by both changes, and stability, in patterns of living arrangements and family structure within the region since the beginning of the 21 st 
century. Recent assessments of the living arrangements of older adults circa 1990 and 2010 (UN, 2017b) indicate that while co-residence with children has retained a stronghold, there have been noteworthy increases in the proportion of the region's older adults who live alone $(9 \%, 1990$ to $13 \%, 2010)$ and those who live with a spouse only $(15 \%, 1990$ to $20 \%, 2010)$. Country differences withstand as countries that are more advanced in the demographic transition, such Argentina and Uruguay, show higher proportions of older adults living alone in 2010 (19\% and $24 \%$, respectively) than other countries in the region. Although it is unclear whether solo living reflects older adults' preferences, the declining availability of kin or structural changes that have offered more opportunities for independent living, studies show that living alone is a risk factor for depression (Ylli et al., 2016). Related to this, a comparative assessment of the 1990 and 2000 censuses recorded an increased proportion of unmarried older adults during this decade in some Latin American countries, specifically Argentina, Mexico and Brazil (Centro Latinoamericano y Caribeño de Demografía (CELADE) et al., 2015). Our findings show that the combination of being unmarried and living alone increased the odds of experiencing depressive symptoms among older adults in urban areas of Latin America and the Caribbean. As the share and numbers of this sub-group of older adults is likely to increase over time, closer attention to this segment of the population is warranted.

We also investigated whether the relationship between family ties, parental and marital status, and mental health are moderated by life stressors such as subjective income adequacy. Our results show that older adults who perceived their income as adequate were less likely to experience depressive symptoms. We further demonstrate that individuals' perceived income adequacy moderated the relationship between marital status and depression, but there was no similar moderating effect for parental status.

Notwithstanding the importance of children as a source of financial and nonfinancial support for older adults, it is encouraging that childless older adults who are economically insecure do not experience higher vulnerability to depression compared to economically insecure parents. It is possible that childless older adults, in earlier periods of their lifecourse, have psychologically prepared for later life without the support of children and have developed the capacity to cope with financial strain. In contrast, relative to married older adults, being unmarried and economically insecure presented a double jeopardy for psychological health, and is intensified among older adults who live alone. Therefore, it is not merely the absence of a spouse/partner, but the presence of additional stressors such as financial strain combined with a lack of immediate access to social resources in the form of co-residential living arrangements, which further reduces access to financial, social and emotional resources to protect one's mental health.

Thus, the economic wellbeing of current and future cohorts of older adults, regardless of their family status, remains one of the most important concerns for social policy. Beginning in the 1990s, several countries have addressed the gap in pension coverage by implementing and extending the scope of their social pension programmes, which increased the total share of older adults receiving a pension (Bosch et al., 2013). Despite these efforts to address older adults' income security, several challenges abound, namely the relative inadequacy of pension income to 
circumvent poverty among those currently receiving a pension, the low rates of contribution among the current working-age population (approximately $45 \%$ of all workers contribute to pension programmes), income inequality, informal labour and the lower labour force participation of women relative to men (Organisation for Economic Co-operation and Development et al., 2014). Latin American and Caribbean governments are challenged to implement public policies to address income-generating opportunities for older adults, incentives for workers to contribute to pension savings such as including informal workers, and reconciliation of work and family responsibilities, to name a few.

Finally, results indicate that the prevalence of depressive symptoms varied across the cities, with older adults in Santiago having higher odds of experiencing depression, whereas those in Bridgetown, Buenos Aires and Havana had lower odds of depression compared to those in São Paulo. Although the association between parental status and elevated depressive symptoms did not differ across cities, there was evidence of contextual differences in the relationship between marital status and depression. Consistent with previous research on later-life depression in urban Latin America and the Caribbean (Alvarado et al., 2007), the absence of a partner was more detrimental to the mental health of older adults in Havana and Montevideo compared to other cities. These context-specific patterns may be due to a constellation of factors such as systematic differences in social welfare, living standards, social norms regarding marriage, the preferred living arrangements of older adults in these cities and levels of social integration, such that older adults can rely on non-kin networks. Nevertheless, the finding implies that family resources, specifically spouses, are important to older adults' psychological health regardless of the strength of institutional support or levels of economic development in different countries across the region. Overall, relative to parental status, marital status had a stronger association with later-life depression, both a direct and indirect stress-buffering effect, among older adults in these cities. As previous studies have identified (Mutran et al., 1995), spouses often take precedence over children and friends as a source of social support in later life and are more likely to influence wellbeing.

Additional sensitivity analyses were conducted to examine gender differences in the relationship between parental status, marital status and depressive symptoms. Given family life within Latin America and the Caribbean is more central to women's social roles relative to men (Salles and Tuirán, 1997; Safa, 2005), it might be expected that childlessness may be more important to women's mental health than men's. The analyses do not support this assumption as results (available in supplementary material online) indicate that there were no statistically significant interaction effects between parental status and gender on depressive symptoms. We did, however, find that the relationship between marital status and depressive symptoms differed by gender (available in supplementary material online). Specifically, unmarried men living alone were more vulnerable to experiencing depressive symptoms. This gender difference may reflect gender differences in social capital as women are more likely to have larger social networks to draw upon for social support, whilst men typically rely on their spouses for emotional support and health behaviour regulation, which can enhance their mental health (Thomas et al., 2017). Therefore, for men, spousal loss and solo living has a stronger 
association with their health. Importantly, disability and health conditions were positively associated with depressive symptoms while having primary educational attainment was protective. These findings reinforce the need for Latin American and Caribbean countries to invest in institutions to support health at older ages, regardless of one's family status.

This study has several limitations. First, the measure of depressive symptoms differed from the measures used in other studies. In this study, participants' depressive symptoms were reported using the GDS-15, with a cut-off score of 4/5. Other studies on the prevalence of depressive symptoms in Latin America and the Caribbean have used other measures, different cut-off points or alternative ways of dealing with item non-response, all of which influence the estimated prevalence rates (Lebrão and Laurenti, 2005; Barcelos-Ferreira et al., 2009; Andrade et al., 2016). A second limitation is related to missing data for depressive symptoms: 7 per cent of those who were cognitively intact, based on a score of 13 or more in the abbreviated Mini-Mental State Examination (MMSE), did not self-report their symptoms. However, a higher percentage of those with cognitive impairment (those who scored 12 or less in the MMSE) had missing data on depressive symptoms. A third limitation of the study is that estimates of depressive symptoms among older adults in these cities may be biased because we did not include respondents living in nursing homes, and depressive symptoms may be higher among this segment of the population. However, this population in Latin America and the Caribbean is small (Camarano and Kanso, 2010; Matus-Lopez and Pedraza, 2015, 2016). Additionally, we could not account for older adults who were biologically childless. The experience of living without children over the course of their lives and mental health implications may differ from those who have outlived their children (Dykstra and Hagestad, 2007). It is also worth noting that the current analyses did not disaggregate the unmarried statuses due to the small sample sizes of never-married adults. Further studies should differentiate among the unmarried, given that older adults who never married may differ from those who became widowed or divorced.

Nevertheless, our study underscores the importance of examining changing family structures and its influence on older adults' psychological wellbeing within rapidly ageing Latin American and Caribbean countries. The findings simultaneously challenge and confirm that familial resources do have significant bearing on later-life mental health for older adults in urban Latin America and the Caribbean. Whilst childlessness did not appear to present a mental health disadvantage, being unmarried was associated with an increased likelihood of depression. The study also highlights the intersection of subjective financial vulnerability and family ties to later-life mental health. Importantly, not having a spouse/partner combined with financial strain compounds mental health declines at older ages in urban Latin America and the Caribbean. Thus, marital relationships remain one of the most important social ties that shape later-life wellbeing, and may be more important than ties to children, for older adults' wellbeing in the region. Future research can further explore longitudinal designs, institutionalised sub-populations, the biologically childless and localised contextual information. Research along these lines will help us better understand the dynamism in the relationship between family ties and mental health. For instance, childlessness may produce an onset of depressive symptoms within the context of changes in other aspects of one's life: marital status, economic security, 
disability and changing living arrangements. Furthermore, research should also address environmental and structural conditions of city contexts, such as the prevalence of crime, poverty and access to health services.

Supplementary material. To view supplementary material for this article, please visit https://doi.org/10. 1017/S0144686X18000879.

Author contributions. NTQ conceptualised the study and contributed to writing the manuscript. FCDA performed all statistical analyses and contributed to writing the manuscript.

Financial support. This research is supported by the Ratchadapisek Somphot Fund for Postdoctoral Fellowship, Chulalongkorn University, Thailand.

\section{References}

Agree EM and Glaser K (2009) Demography of informal caregiving. In Uhlenberg P (ed.), International Handbook of Population Aging. Dordrecht, The Netherlands: Springer, pp. 647-668.

Almeida OP and Almeida SA (1999) Reliability of the Brazilian version of the Geriatric Depression Scale (GDS) short form. Arquivos de Neuro-Psiquiatria 57, 421-426.

Alvarado BE, Zunzunegui MV, Beland F, Sicotte M and Tellechea L (2007) Social and gender inequalities in depressive symptoms among urban older adults of Latin America and the Caribbean. Journals of Gerontology: Psychological Sciences and Social Sciences 62B, S226-S236.

Andrade FCD, Wu F, Lebrão ML and Duarte YAdO (2016) Life expectancy without depression increases among Brazilian older adults. Revista de Saúde Pública 50. doi: 10.1590/S1518-8787.2016050005900.

Angel RJ, Frisco M, Angel JL and Chiriboga DA (2003) Financial strain and health among elderly Mexican-origin individuals. Journal of Health and Social Behavior 44, 536-551.

Arber S (2004) Gender, marital status, and ageing: linking material, health, and social resources. Journal of Aging Studies 18, 91-108.

Arber S, Fenn K and Meadows R (2014) Subjective financial well-being, income and health inequalities in mid and later life in Britain. Social Science \& Medicine 100, 12-20.

Atun R, De Andrade LOM, Almeida G, Cotlear D, Dmytraczenko T, Frenz P, Garcia P, Gómez-Dantés O, Knaul FM and Muntaner C (2015) Health-system reform and universal health coverage in Latin America. The Lancet 385, 1230-1247.

Barcelos-Ferreira R, Pinto JA, Nakano EY, Steffens DC, Litvoc J and Bottino CMC (2009) Clinically significant depressive symptoms and associated factors in community elderly subjects from Sao Paulo, Brazil. American Journal of Geriatric Psychiatry 17, 582-590.

Bertranou FM (2006) Pensions and gender in Latin America: where do we stand in the Southern Cone? Gender Issues 23, 6-31.

Bongaarts J and Zimmer Z (2002) Living arrangements of older adults in the developing world: an analysis of demographic and health survey household surveys. Journals of Gerontology: Psychological Sciences and Social Sciences 57B, S145-S157.

Bosch M, Melguizo Á and Pagés C (2013) Better Pensions, Better Jobs: Towards Universal Coverage in Latin America and the Caribbean. Washington, DC: Inter-American Development Bank.

Brailean A, Guerra M, Chua K-C, Prince M and Prina MA (2015) A multiple indicators multiple causes model of late-life depression in Latin American countries. Journal of Affective Disorders 184, 129-136.

Brown SL and Wright MR (2017) Marriage, cohabitation, and divorce in later life. Innovation in Aging 1. doi: 10.1093/geroni/igx015.

Brundenius C (2002) Whither the Cuban economy after recovery? The reform process, upgrading strategies and the question of transition. Journal of Latin American Studies 34, 365-395.

Buber I and Engelhardt H (2008) Children's impact on the mental health of their older mothers and fathers: findings from the Survey of Health, Ageing and Retirement in Europe. European Journal of Ageing 5, 31-45.

Burke WJ, Roccaforte WH and Wengel SP (1991) The short form of the Geriatric Depression Scale: a comparison with the 30-item form. Journal of Geriatric Psychiatry and Neurology 4, 173-178. 
Calvo E and Williamson JB (2008) Old-age pension reform and modernization pathways: lessons for China from Latin America. Journal of Aging Studies 22, 74-87.

Camarano AA and Kanso S (2010) As instituições de longa permanência para idosos no Brasil. Revista Brasileira de Estudos de População 27, 232-235.

Carvalhais S, Lima-Costa M, Peixoto S, Firmo J, Castro-Costa E and Uchoa E (2008) The influence of socio-economic conditions on the prevalence of depressive symptoms and its covariates in an elderly population with slight income differences: the Bambui Health and Aging Study (BHAS). International Journal of Social Psychiatry 54, 447-456.

Centro Latinoamericano y Caribeño de Demografía (CELADE), División de Población de la Comisión Económica para América Latina y El Caribe (CEPAL) and Naciones Unidas (2015) Sistema Regional de Indicadores sobre Envejecimiento-SISE. Available at http://redatam.org/redatam/pryesp/madrid/.

Chang E, Wilber KH and Silverstein M (2010) The effects of childlessness on the care and psychological well-being of older adults with disabilities. Aging and Mental Health 14, 712-719.

Cheng S-T, Chan TWS, Li GH and Leung EM (2013) Childlessness and subjective well-being in Chinese widowed persons. Journals of Gerontology: Psychological Sciences and Social Sciences 69B, 48-52.

Chou KL and Chi I (2004) Childlessness and psychological well-being in Chinese older adults. International Journal of Geriatric Psychiatry 19, 449-457.

Chou K-L, Ho A and Chi I (2006) Living alone and depression in Chinese older adults. Aging and Mental Health 10, 583-591.

Cohen B (2006) Urbanization in developing countries: current trends, future projections, and key challenges for sustainability. Technology in Society 28, 63-80.

Connidis IA (2010) Family ties and aging. Thousand Oaks, CA: Pine Forge Press.

Cotlear D (2011) Population Aging: Is Latin America Ready? Washington, DC: World Bank.

Cotlear D and Tornarolli L (2011) Poverty, the aging and the life cycle in Latin America. In Cotlear D (ed.), Population Aging: Is Latin America Ready? Washington, DC: World Bank, pp. 79-134.

Dalgard OS, Dowrick C, Lehtinen V, Vazquez-Barquero JL, Casey P, Wilkinson G, Ayuso-Mateos JL, Page H, Dunn G and Group O (2006) Negative life events, social support and gender difference in depression. Social Psychiatry and Psychiatric Epidemiology 41, 444-451.

Davey A, Femia EE, Zarit SH, Shea DG, Sundström G, Berg S, Smyer MA and Savla J (2005) Life on the edge: patterns of formal and informal help to older adults in the United States and Sweden. Journals of Gerontology: Psychological Sciences and Social Sciences 60B, S281-S288.

De Ferranti D, Perry GE, Ferreira FHG and Walton M (2004) Inequality in Latino America and the Caribbean: Breaking with History? Washington, DC: World Bank Latin American and Caribbean Studies.

De Vos S (2012) On the role of the extended family in helping to pay for the household expenses of unmarried older women (60+) in Latin America and the Caribbean. Journal of Comparative Family Studies 43, 787-809.

De Vos S (2014) Biologically childless women 60+ often live in extended family households in Latin America. Journal of Cross-cultural Gerontology 29, 467-480.

Djundeva M, Emery T and Dykstra PA (2017) Parenthood and depression: is childlessness similar to sonlessness among Chinese seniors? Ageing \& Society. Available online doi:10.1017/ S0144686X1700054X.

Dykstra PA and Hagestad GO (2007) Childlessness and parenthood in two centuries: different roads - different maps? Journal of Family Issues 28, 1518-1532.

Economic Commission for Latin America and the Caribbean (2010) Statistical Yearbook for Latin America and the Caribbean 2010. Santiago: CEPAL.

Elder GH and Johnson MK (2003) The life course and aging: challenges, lessons, and new directions. In Settersten RA (ed.), Invitation to the Life Course: Toward New Understandings of Later Life. New York: Baywood, pp. 49-81.

Ferrari AJ, Charlson FJ, Norman RE, Patten SB, Freedman G, Murray CJ, Vos T and Whiteford HA (2013) Burden of depressive disorders by country, sex, age, and year: findings from the global burden of disease study 2010. PLOS Medicine 10, e1001547.

Fry PS (2001) The unique contribution of key existential factors to the prediction of psychological wellbeing of older adults following spousal loss. The Gerontologist, 41, 69-81. 
García B and De Oliveira O (2011) Family changes and public policies in Latin America. Annual Review of Sociology 37, 593-611.

Gaymu J and Springer S (2010) Living conditions and life satisfaction of older Europeans living alone: a gender and cross-country analysis. Ageing \& Society 30, 1153-1175.

Gildner TE, Liebert MA, Capistrant BD, D'Este C, Snodgrass JJ and Kowal P (2016) Perceived income adequacy and well-being among older adults in six low- and middle-income countries. Journals of Gerontology: Psychological Sciences and Social Sciences. doi: 10.1093/geronb/gbw145.

Greenfield EA and Russell D (2011) Identifying living arrangements that heighten risk for loneliness in later life: evidence from the US National Social Life, Health, and Aging Project. Journal of Applied Gerontology 30, 524-534.

Grundy E, van den Broek T and Keenan K (2017) Number of children, partnership status, and later-life depression in Eastern and Western Europe. Journals of Gerontology: Psychological Sciences and Social Sciences. doi: 10.1093/geronb/gbx050.

Guerra M, Ferri CP, Sosa AL, Salas A, Gaona C, Gonzales V, de la Torre GR and Prince M (2009) Late-life depression in Peru, Mexico and Venezuela: the 10/66 population-based study. British Journal of Psychiatry 195, 510-515.

Guerra M, Prina AM, Ferri CP, Acosta D, Gallardo S, Huang Y, Jacob KS, Jimenez-Velazquez IZ, Llibre Rodriguez JJ, Liu Z, Salas A, Sosa AL, Williams JD, Uwakwe R and Prince M (2016) A comparative cross-cultural study of the prevalence of late life depression in low and middle income countries. Journal of Affective Disorders 190, 362-368.

Guo M (2014) Parental status and late-life well-being in rural China: the benefits of having multiple children. Aging and Mental Health 18, 19-29.

Guo M, Chi I and Silverstein M (2012) The structure of intergenerational relations in rural China: a latent class analysis. Journal of Marriage and Family 74, 1114-1128.

Haberkern K and Szydlik M (2010) State care provision, societal opinion and children's care of older parents in 11 European countries. Ageing \& Society 30, 299-323.

Haggard S and Kaufman RR (2008) Development, Democracy, and Welfare States: Latin America, East Asia, and Eastern Europe. Princeton, NJ: Princeton University Press.

Hank K and Wagner M (2013) Parenthood, marital status, and well-being in later life: evidence from SHARE. Social Indicators Research 114, 639-653.

Hansen T, Slagsvold B and Moum T (2009) Childlessness and psychological well-being in midlife and old age: an examination of parental status effects across a range of outcomes. Social Indicators Research $\mathbf{9 4}$, 343-362.

Huenchuan S (2013) Ageing, Solidarity and Social Protection in Latin America and the Caribbean: Time for Progress Towards Equality. Santiago: ECLAC.

Huijts T, Kraaykamp G and Subramanian S (2013) Childlessness and psychological well-being in context: a multilevel study on 24 European countries. European Sociological Review 29, 32-47.

Kamiya Y, Doyle M, Henretta JC and Timonen V (2013) Depressive symptoms among older adults: the impact of early and later life circumstances and marital status. Aging and Mental Health 17, 349-357.

Koropeckyj-Cox T (1998) Loneliness and depression in middle and old age: are the childless more vulnerable? Journals of Gerontology: Psychological Sciences and Social Sciences 53B, S303-S312.

Lebrão ML and Laurenti R (2005) Saúde, bem-estar e envelhecimento: o estudo SABE no município de São Paulo. Revista brasileira de epidemiologia 8, 127-141.

Litwin H and Sapir EV (2009) Perceived income adequacy among older adults in 12 countries: findings from the Survey of Health, Ageing, and Retirement in Europe. The Gerontologist 49, 397-406.

Liu $\mathbf{H}$ and Waite L (2014) Bad marriage, broken heart? Age and gender differences in the link between marital quality and cardiovascular risks among older adults. Journal of Health and Social Behavior 55, 403-423.

Mair CA (2013) Family ties and health cross-nationally: the contextualizing role of familistic culture and public pension spending in Europe. Journals of Gerontology: Psychological Sciences and Social Sciences 68B, 984-996.

Matus-Lopez M and Pedraza CC (2015) Building long-term care policies in Latin America: new programs in Chile. Journal of the American Medical Directors Association 16, 900.e7-900.e10.

Matus-Lopez M and Pedraza CC (2016) New long-term care policies in Latin America: the national system of care in Uruguay. Journal of the American Medical Directors Association 17, 663-665. 
Medici AC (2011) How age influences the demand for health care in Latin America. In Cotlear D (ed.), Population Aging: Is Latin America Ready. Washington, DC: World Bank, pp. 135-189.

Mesa-Lago C (2005) Social and economic problems in Cuba during the crisis and subsequent recovery. CEPAL Review. 86, 177-199.

Mesa-Lago C (2009) Social insurance (pensions and health), labour markets and coverage in Latin America. In Hujo K and McClanahan S (eds), Financing Social Policy. London: Palgrave Macmillan, pp. 215-245.

Min J, Li Y, Xu L and Chi I (2017) Psychological vulnerability of widowhood: financial strain, social engagement and worry about having no care-giver as mediators and moderators. Ageing \& Society. Available online doi:10.1017/S0144686X17000654.

Mutran EJ, Reitzes DC, Mossey J and Fernandez ME (1995) Social support, depression, and recovery of walking ability following hip fracture surgery. Journals of Gerontology: Psychological Sciences and Social Sciences 50B, S354-S361.

Nam VE (2009) National Census Report: Barbados. Guyana: CARICOM. Available at http://www.caricomstats.org/Files/Publications/NCR\%20Reports/Barbados.pdf.

Neuberger FS and Preisner K (2018) Parenthood and quality of life in old age: the role of individual resources, the welfare state and the economy. Social Indicators Research 138, 353-372.

Organisation for Economic Co-operation and Development, Inter-American Development Bank and the World Bank (2014) Pensions at a Glance: Latin America and the Caribbean. Paris: OECD Publishing. Available at http://www.oecd.org/publications/oecd-pensions-at-a-glance-pension-glance2014-en.htm.

Palloni A (2001) Living arrangements of older persons. In United Nations (ed.), Population Ageing and Living Arrangements of Older Persons: Critical Issues and Policy Concerns. New York, NY: United Nations, Available at http://www.un.org/esa/population/publications/bulletin42_43/palloni.pdf

Pan American Health Organization (2017) Health in the Americas + 2017 Edition: Summary Regional Outlook and Country Profiles. Washington, DC: Pan American Health Organization. Available at http://iris.paho.org/xmlui/handle/123456789/34321.

Parker S and Wong R (2001) Welfare of male and female elderly in Mexico: a comparison. In Katz EG and Correia MC (eds), The Economics of Gender in Mexico: Work, Family, State, and Market. Washington, DC: World Bank, pp. 249-290.

Peláez M, Palloni A, Alba C, Alfonso JC, Ham-Chande R, Hennis R, Lebrão ML, León-Díaz E, Pantelides A and Pratts O (2006) SABE - Survey on Health, Well-Being, and Aging in Latin America and the Caribbean, 2000. Ann Arbor, MI: Inter-university Consortium for Political and Social Research [distributor], 2006-02-17. doi:10.3886/ICPSR03546.v1.

Pettinato S and Cassou JD (2005) A needs assessment of pension systems in the English-speaking Caribbean. In Brunton DP and Masci P (eds), Workable Pension Systems: Reforms in the Caribbean. Washington, DC: Inter-American Development Bank, pp. 59-96.

Rao JNK and Scott AJ (1984) On chi-squared tests for multiway contingency tables with cell proportions estimated from survey data. Annals of Statistics 12, 46-60.

Rook KS (2015) Social networks in later life: weighing positive and negative effects on health and wellbeing. Current Directions in Psychological Science 24, 45-51.

Rosero Bixby L, Castro Martín T and Martín García T (2009) Is Latin America starting to retreat from early and universal childbearing? Demographic Research 20, 169-194.

Saad P (2011) Demographic trends in Latin America and the Caribbean. In Cotlear D (ed.), Population Aging: Is Latin America Ready? Washington, DC: World Bank, pp. 43-77.

Safa H (2005) The matrifocal family and patriarchal ideology in Cuba and the Caribbean. Journal of Latin American Anthropology 10, 314-338.

Salles V and Tuirán R (1997) The family in Latin America: a gender approach. Current Sociology 45, 141-152.

Schwarzbach M, Luppa M, Forstmeier S, König HH and Riedel-Heller SG (2014) Social relations and depression in late life - a systematic review. International Journal of Geriatric Psychiatry 29, 1-21.

Sicotte M, Alvarado BE, León E-M and Zunzunegui M-V (2008) Social networks and depressive symptoms among elderly women and men in Havana, Cuba. Aging and Mental Health 12, 193-201.

Tajvar M, Fletcher A and Grundy E (2016) Exploring associations between social support and mental health in older people: a systematic narrative review. International Journal on Ageing in Developing Countries 1, 174-193. 
Thoits PA (2011) Mechanisms linking social ties and support to physical and mental health. Journal of Health and Social Behavior 52, 145-161.

Thomas PA, Liu H and Umberson D (2017) Family relationships and well-being. Innovation in Aging 1. doi: 10.1093/geroni/igx025.

Umberson D, Pudrovska T and Reczek C (2010) Parenthood, childlessness, and well-being: A life course perspective. Journal of Marriage and Family 72, 612-629.

Umberson D, Thomeer MB and Williams K (2013) Family status and mental health: recent advances and future directions. In Aneshensel CL, Phelan JC and Bierman A (eds), Handbook of the Sociology of Mental Health. Dordrecht, The Netherlands: Springer, pp. 405-431.

United Nations (UN) (2005) Living Arrangements of Older Persons Around the World. New York, NY: United Nations.

United Nations (UN) (2010) Population and Development 2009. New York, NY: United Nations. Available at http://www.un.org/esa/population/publications/ageing/ageing2009.htm.

United Nations (UN) (2014) World Urbanization Prospects: The 2014 Revision, Highlights. New York, NY: United Nations Department of Economic and Social Affairs, Population Division. Available at https:// esa.un.org/unpd/wup/DataQuery/.

United Nations (UN) (2017a) World Population Prospects: The 2017 Revision. New York, NY: United Nations Department of Economic and Social Affairs, Population Division. Available at https://esa.un. org/unpd/wpp/DataQuery/.

United Nations (UN) (2017b) Living Arrangements of Older Persons: A Report on an Expanded International Dataset (ST/ESA/SER.A/407). New York, NY: United Nations Department of Economic and Social Affairs, Population Division. Available at http://www.un.org/en/development/desa/population/publications/pdf/ageing/LivingArrangements.pdf.

Wong R, Pelaez M, Palloni A and Markides K (2006) Survey data for the Study of Aging in Latin America and the Caribbean: selected studies. Journal of Aging and Health 18, 157-179.

World Bank (2017) World Development Indicators. Washington, DC: World Bank. Available at http://databank.worldbank.org/data/reports.aspx?source=world-development-indicators.

Yesavage JA, Brink TL, Rose TL, Lum O, Huang V, Adey M and Leirer VO (1983) Development and validation of a geriatric depression screening scale: a preliminary report. Journal of Psychiatric Research 17, 37-49.

Yesavage JA and Sheikh JI (1986) Geriatric Depression Scale (GDS): recent evidence and development of a shorter version. Clinical Gerontologist 5, 165-173.

Ylli A, Miszkurka M, Phillips SP, Guralnik J, Deshpande N and Zunzunegui MV (2016) Clinically relevant depression in old age: an international study with populations from Canada, Latin America and Eastern Europe. Psychiatry Research 241, 236-241.

Zhang B and Li J (2011) Gender and marital status differences in depressive symptoms among elderly adults: the roles of family support and friend support. Aging and Mental Health 15, 844-854.

Zhang W and Liu G (2007) Childlessness, psychological well-being, and life satisfaction among the elderly in China. Journal of Cross-cultural Gerontology 22, 185-203.

Zhang Z and Hayward MD (2001) Childlessness and the psychological well-being of older persons. Journals of Gerontology: Psychological Sciences and Social Sciences 56B, S311-S320.

Cite this article: Quashie NT, Andrade FCD (2020). Family status and later-life depression among older adults in urban Latin America and the Caribbean. Ageing \& Society 40, 233-261. https://doi.org/ $10.1017 /$ S0144686X18000879 